\title{
HYBRID FIXED POINT THEORY IN PARTIALLY ORDERED NORMED LINEAR SPACES AND APPLICATIONS TO FRACTIONAL INTEGRAL EQUATIONS
}

\begin{abstract}
BAPURAO C. DHAGE
Abstract. In this paper, some basic hybrid fixed point theorems of Banach and Schauder type and some hybrid fixed point theorems of Krasnoselskii type involving the sum of two operators are proved in a partially ordered normed linear spaces which are further applied to nonlinear Volterra fractional integral equations for proving the existence of solutions under certain monotonic conditions blending with the existence of either a lower or an upper solution type function.
\end{abstract}

Mathematics subject classification (2010): 45G10, 45M99, 47H09, 47H10.

Keywords and phrases: Hybrid fixed point theorem, Partially ordered normed linear space, Fractional integral equation, Existence theorem.

\section{REFERENCES}

[1] H. Amann, Order Structures and Fixed Points, ATTI $2^{\circ}$ Sem. Anal. Funz. Appl., Itali, (1977).

[2] G. Birkhoff, Lattice Theory, Amer. Math. Soc. Coll. Publ. 1947.

[3] F. E. BRowDER, Nonlinear Operators and Nonlinear Equations of Evolution in Banach Spaces, Proc. Symp. Pure Math. Amer. Math. Soc., Providence, Rhode Island 1976.

[4] K. Deimling, Nonlinear Functional Analysis, Springer-Verlag, Berlin, 1985.

[5] B. C. Dhage, On extension of Tarski's fixed point theorem and applications, Pure Appl. Math. Sci., 25 (1987), 37-42.

[6] B. C. DHAGE, Some fixed point theorems for in ordered Banach spaces and applications, Mathematics Student, 61 (1992), 81-88.

[7] B. C. Dhage, Fixed point theorems in ordered Banach algebras and applications, Pan Amer. Math. J., 9, (4) (1999), 93-102.

[8] B. C. DHAGE, A nonlinear alternative with applications to nonlinear perturbed differential equations, Nonlinear Studies, 13, (4) (2006), 343-354.

[9] B. C. DhaGE AND N. S. JADHAV, Basic results on hybrid differential equations with linear perturbation of second type, Tamkang J. Math., 43, (4) (2013), 00-00.

[10] B. C. Dhage And P. V. Mugale, On Some Basic Results for Nonlinear First Order Hybrid Fractional Differential Equations, Comm. Appl. Nonlinear Anal., 19 (2012), 83-96.

[11] A. Granas and J. Dugundu, Fixed Point Theory, Springer-Verlag, New York, 2003.

[12] A. Granas, R. B. Guenther And J. W. Lee, Some general existence principles in the Carathéodary theory of nonlinear differential systems, J. Math. Pures Appl., 70 (1991), 153-198.

[13] S. Heik KIL ̈̈ AND V. LAKshmik Antham, Monotone Iterative Techniques for Discontinuous Nonlinear Differential Equations, Marcel Dekker inc., New York 1994.

[14] M. A. KRASNOSELSKII, Topological Methods in the Theory of Nonlinear Integral Equations, Pergamon Press 1964.

[15] A. A. Kilbas, H. M. SRivastava and Juan Trujillo, Theory and Applications of Fractional Differential Equations, North Holland Mathematics Series, 204, Elsevier Science B. V. Amsterdam, 2006.

[16] V. Lakshmikantham, S. Leela and J. Vasundhara DeVi, Theory of fractional dynamic systems, Cambridge Scientific Publishers, (2009). 
[17] J. J. Nieto AND R. RodrigueZ-LopeZ, Contractive mappings theorems in partially ordered sets and applications to ordinary differential equations, Order 22 (2005), 223-239.

[18] J. J. NiETO AND R. RODRIGUEZ-LOPEZ, Existence and uniqueness of fixed point in partially ordered sets and applications to ordinary differential equations, Acta Math. Sinica (English Series), 23 (2007), 2205-2212.

[19] I. Podlubny, Fractional Differential Equations, Academic Press New York 1999.

[20] A. C. M. RAN, M.C. R. REURINGS, A fixed point theorem in partially ordered sets and some applications to matrix equations, Proc. Amer. Math. Soc. 132 (2003), 1435-1443.

[21] A. TARSKI, A lattice theoretical fixed-point theorem and its applications, Pacific J. Math., 5 (1955), $285-310$.

[22] E. ZeIdLer, Nonlinear Functinal Analysis and its Applications: Part I, Springer Verlag 1985. 